\title{
The Evaluation of Root Fracture with Cone Beam Computed Tomography (CBCT): An Epidemiological Study
}

\author{
Mehmet-Sinan Doğan ${ }^{1}$, Michele Callea ${ }^{2}$, Lindawati S. Kusdhany ${ }^{3}$, Ahmet Aras ${ }^{4}$, Diah-Ayu Maharani ${ }^{5}$, Masi- \\ ta Mandasari ${ }^{6}$, Melissa Adiatman ${ }^{5}$, Izzet Yavuz ${ }^{4}$
}

\footnotetext{
${ }^{1}$ Harran University, Faculty of Dentistry, Department of Pediatric Dentistry,Şanlıurfa, Türkiye

${ }^{2}$ Unit of Dentistry, Bambino Gesù Children's Hospital, IRCCS, Rome, Italy

${ }^{3}$ Prosthodontic Department, Faculty of Dentistry, Universitas Indonesia

${ }^{4}$ Oral and Tooth Health Center, Department of Pediatric Dentistry, Diyarbakir, Türkiye

${ }^{5}$ Department of Preventive and Public Health Dentistry, Faculty of Denstistry, Universitas Indonesia

${ }^{6}$ Departement of Oral Medicine, Faculty of Dentistry, Universitas Indonesia, Jakarta, Indonesia
}

Correspondence:

Dicle University, Faculty of Dentistry

Department of Pediatric Dentistry

21280 Diyarbakir / TURKEY

izzetyavuz@hotmail.com

Received: 03/05/2017

Accepted: $18 / 11 / 2017$

\begin{abstract}
Doğan MS, Callea M, Kusdhany LS, Aras A, Maharani DA, Mandasari M, Adiatman M, Yavuz I. The Evaluation of Root Fracture with Cone Beam Computed Tomography (CBCT): An Epidemiological Study. J Clin Exp Dent. 2018;10(1):e41-8.

http://www.medicinaoral.com/odo/volumenes/v10i1/jcedv10ilp41.pdf
\end{abstract}

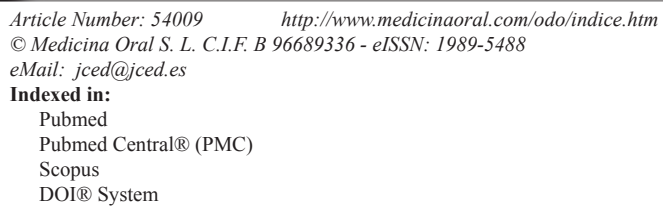

\begin{abstract}
Background: The aim of this study was evaluation of the cone-beam computed tomography (CBCT) image of 50 patients at the ages of 8-15 suspecting root fracture and root fracture occurred, exposed to dental traumatic. In additionally, this study was showed effect of crown fracture on root fracture healing.

Material and Methods: All of the individuals included in the study were obtained images with the cone-beam computed tomography range of 0,3 voxel and 8.9 seconds.(i-CAT®, Model 17-19, Imaging SciencesInternational, Hatfield, Pa USA).The information obtained from the history and CBCT images of patients were evaluated using chi-square test statistical method the mean and the distribution of the independent variables.

Results: 50 children, have been exposed to trauma, was detected root fracture injury in 97 teeth. Horizontal root fracture $63.9 \%$ of the 97 tooth, the oblique in $31.9 \%$, both the horizontal and oblique in $1.03 \%$, partial fracture in $2.06 \%$, and both horizontally and vertical in $1.03 \%$ was observed.The most affected teeth, respectively of, are the maxillary central incisor (41.23\% left, right, $37.11 \%)$, maxillary left lateral incisor (9.27\%), maxillary right lateral incisor (11.34\%), and mandibular central incisor (1.03\%).

Conclusions: Crown fractures have negative effects on spontaneous healing of root fractures. CBCT are used selected as an alternative to with conventional radiography for diagnosis of root fractures. In particular, 1t's cross-sectional image is quite useful and has been provided more conveniences seeing the results of diagnosis and treatment for clinician.
\end{abstract}

Key words: Root fracture, CBCT, Epidemiolog. 


\section{Introduction}

Popularization of preventive dentistry applications, the frequency of dental caries and periodontal problems in children decreased, but epidemiological researches showed that trauma-based dental injuries are still serious problems in children (1-3). Root fractures are less widespread compared to other injuries in classification dental-trauma. Root fractures represent $0.5-7 \%$ of injuries in permanent teeth and $2-4 \%$ of injuries in primary teeth $(4,5)$.

Root fracture is most important in permanent teeth. Root fracture healing is effect of location of fracture, type, root developing and distance of between fracture fragments. The fractures which occurred in the root due to trauma are classified as crown, medium and apical third based on their localization. According to fracture line, root fractures are classified as horizontal, oblique, vertical and horizontal/oblique (4).

Healing of root fractures was classified into four groups according to Andreasen and Hjørting-Hansen: (4).

1. Healing with hard tissue: contact points between fracture fragments are closed and fracture line disappeared or can only be traced very ambiguously.

2. Hard tissue and soft tissue accumulation between fracture fragments.

3. Healing with soft tissue accumulation between fracture fragments: radiolucent areas can be seen between fracture parts in radiography.

4. No healing: Because of pulp necrosis, radiolucent areas can be seen between fracture fragments and in alveolar bone in radiography.

In traditional and digital oral $\mathrm{x}$-ray graphs, dental structures have seen in 2-D form. However, with Cone Beam Computed Tomography (CBCT) which recently is being used in dentistry, anatomic structure of the teeth and the mouth can be observed in any section and plane desired in a 3-D form. Thus, considerable advantage and convenience is obtained in diagnosis of occurred root fractures because of dental injuries (6-10).

Axial, coronal, sagittal and cross-sectional images can be obtained from the data provided by CBCT devices; as a result, it is now possible to identify in a more detailed and accurate manner fractures which are diagnosed or otherwise by traditional radiographies (9).

CBCT device provides to clinician with a wide area of usage for evaulation of dental fractures, cracks, measuring the size of periapical lesions, assessment of bone density in lesion area, endodontic surgery, implant planning, and analysis of temporomandibular joints and resorptions (11-14).

The dose of radiation is varies depending on the CBCT device, especially differences in scanning times and model and usage type of the device (15). The amount of radiation is directly related to the period of image taking and the field of image. For this reason, it is recommen- ded that images are taken with as less field as possible and practicable. It imaging ensures clinicians with submillimeter spatial resolution images of high diagnostic standard with comparatively short scanning times (1070 seconds) and a reported radiation dose same to that required for 4 - 15 panoramic radiographs (16).

The purpose of this study is to evaluate the CBCT image taken from 50 patients between 8-15 years of age who were subject to dental trauma.

\section{Material and Methods}

In this study, CBCT images were taken and examined of 50 patients between 8 and 15 years of age were taken who applied to Dicle University, Faculty of Dentistry, Department of Pediatric Dentistry who were subject to trauma and suspected of dental root fracture. Before CBCT scans was taken, relatives of patients were informed about $\mathrm{CBCT}$ and the approval of the patient was obtained.

Only patients with anterior teeth fracture who were 8-15 years of age and healthy individuals were included in this study. The medical treatment history of patients who were included in this study was explored and information on the patients was collected by means of anamneses forms.

This study was confirmed by the ethical board of Dicle University, Faculty of Medicine on 8th December, 2011. From all individuals included in this study, images were obtained in 8.9 seconds with CBCT device (i-CAT ${ }^{\circ}$, Model 17-19, Imaging Sciences International, Hatfield, Pa USA) (Figs. 1-4).

The teeth with post-trauma luxation were splinted. Generally orthodontic wire - composite splint was applied so that physiological movement of teeth could be allowed $(0.5 \mathrm{~mm}$ full circle orthodontic wire, Kuraray $3 \mathrm{M}$ ESPE composite).

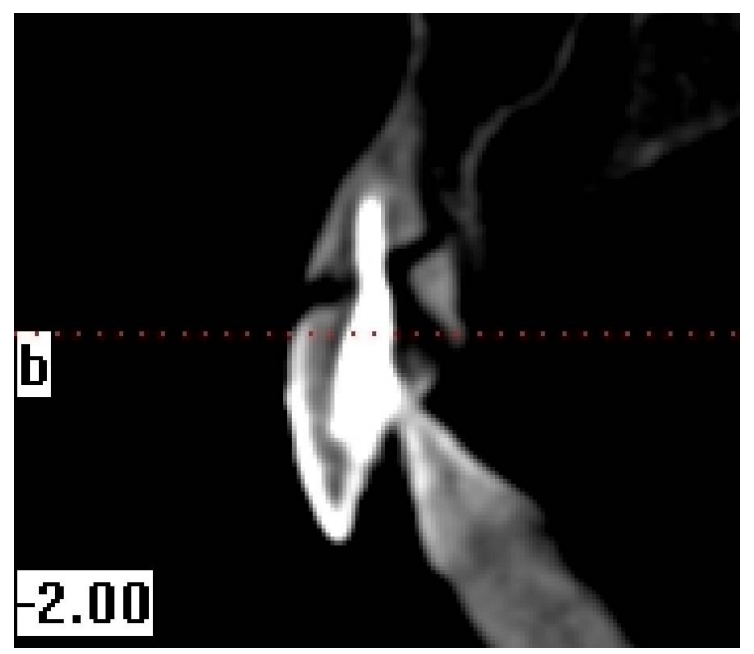

Fig. 1: Cross sectional view oblique root fracture (right upper incisor tooth). 


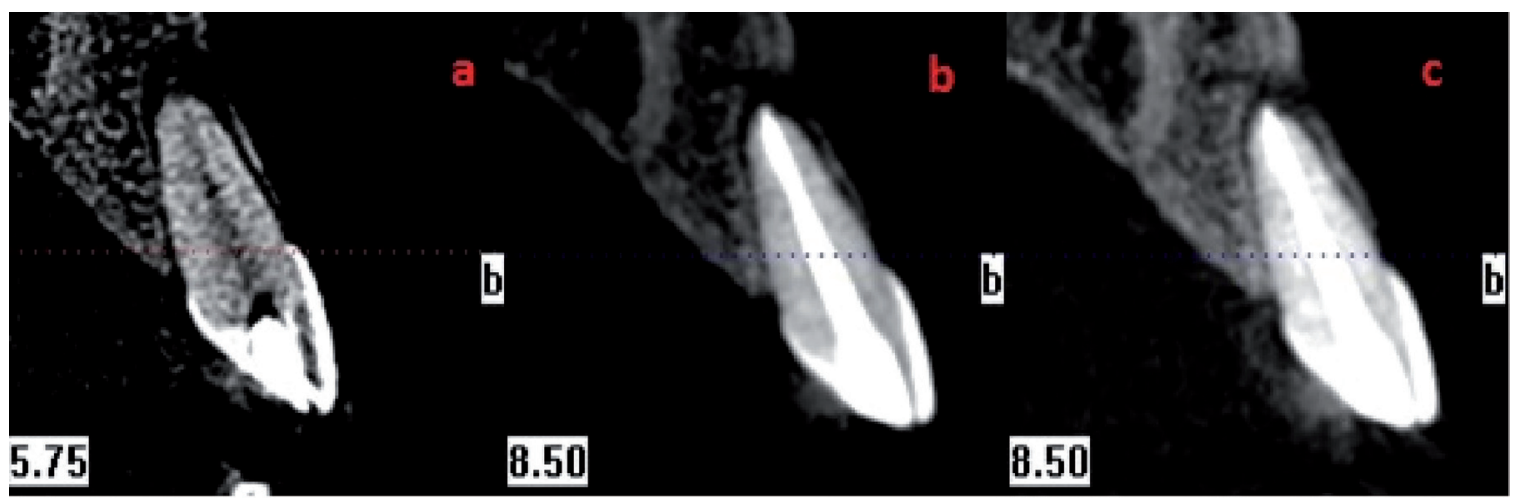

Fig. 2: Apical 1/3 and horizontal root fracture. Pretreatment CBCT view (a), post treatment CBCT view (b), control CBCT view (c).

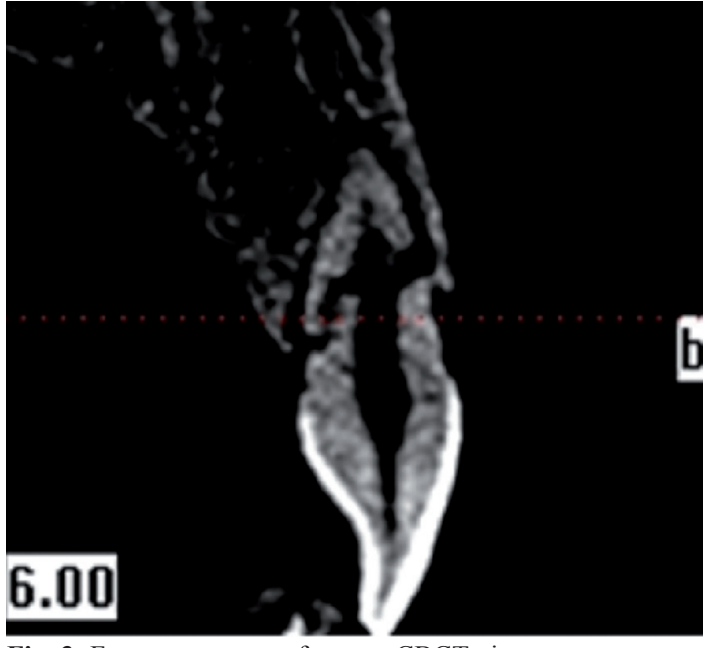

Fig. 3: Fragmentary root fracture $\mathrm{CBCT}$ view.

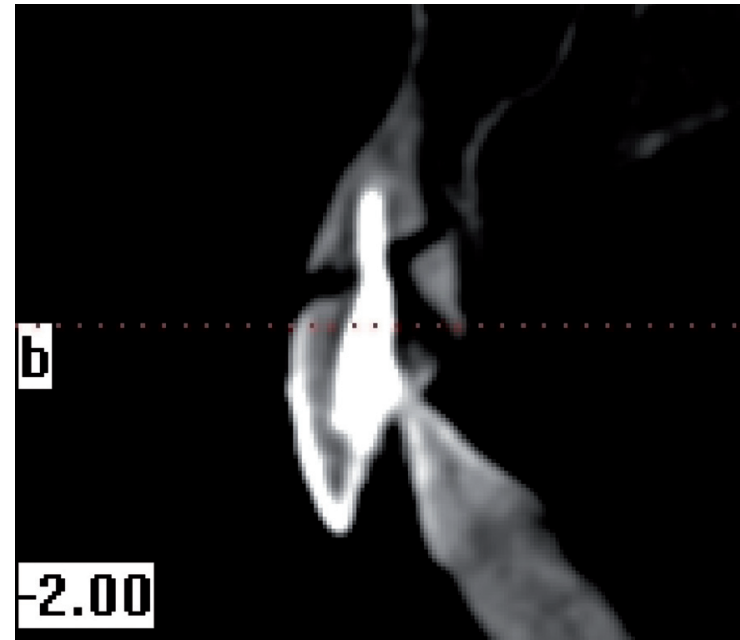

Fig. 4: Apical 1/3 horizontal root fracture and cronal $1 / 3$ vertical root fracture.

Endodontic treatments were applied to the teeth with pulp necrosis. In patients that include pulp but who did not experience pulp necrosis were treated with partial pulptomy and dental vitality was maintained.

In teeth with crown fracture, composite restoration was performed so as to reinstate aesthetic and function in relatively low damage cases (KURARAY 3M ESPE) and intra-canal post-aided restorations (fiber post, prefabricate post) were performed in relatively high damage cases.

\section{Results}

Root fracture injuries were identified in a total of 97 teeth of the 50 children between 8 and 15 years of age who were exposed to trauma. It has been observed that frequency of root fractures was higher in boys (60\%) compared to girls $(40 \%)$. When the distribution of root fractures was examined based on age, it has been found out that injuries were more widespread in children 11-13 years of age. When the number of root fractures occurred in different age groups was examined, significant difference was observed between groups based on gender according to chi-square test (Table $1, P<0.05$ ).

Table 2 gives the distribution and type of root fractures numbers obtained as a result of the evaluation of radiographic and CBCT images of the 50 patients.

As a result of more detailed analysis of the images obtained with CBCT, it has been observed that of the 97 teeth, $63.9 \%$ had horizontal root fracture, $31.9 \%$ had oblique root fracture, $1.03 \%$ had both horizontal and oblique root fracture, 2.06 had fragmentary fracture and 1.03\% had both horizontal and vertical root fracture. An examination of the root fractures showed that 96 of the 97 teeth were maxillary teeth and 1 was mandibular tooth. The most affected teeth were determined as maxillary central incisor teeth $(41.23 \%$ right $37.11 \%$ left), maxillary right lateral incisor teeth (11.34\%), maxillary left lateral incisor teeth $(9.27 \%)$ and mandibular central incisor teeth $(1.03 \%)$ (Table 2).

Fracture location of the 62 teeth which had horizontal root fracture, 11 teeth were at the middle region of the root, 4 teeth were in cervical region, and 47 were in the $1 / 3$ apical region of root. Fracture of the 31 teeth which had oblique root fracture, 20 were in 1/3 apical region, 10 were in middle region and 1 was in cervical region. When the teeth with root fracture were examined as 
Table 1: Investigation of age groups according to the number of root fracture.

\begin{tabular}{|l|c|c|c|c|c|c}
\hline \multicolumn{1}{|c|}{ Sex } & & \multicolumn{3}{|c|}{ Groups of Age } & Total & \multirow{2}{*}{$\boldsymbol{P}$} \\
\hline & & $\mathbf{8 - 1 0}$ & $\mathbf{1 1 - 1 3}$ & $\mathbf{1 4 - 1 5}$ & & \\
\hline Female & Number of root fractures & 13 & 24 & 2 & 39 & \\
\hline & Rate $\%$ & $65,0 \%$ & $40,0 \%$ & $11,8 \%$ & $40,2 \%$ & \\
\hline Male & Number of root fractures & 7 & 36 & 15 & 58 &, $004^{*}$ \\
\hline & Rate $\%$ & $35,0 \%$ & $60,0 \%$ & $88,2 \%$ & $59,8 \%$ & \\
\hline Total & Number of root fractures & 20 & 60 & 17 & 97 & \\
\hline
\end{tabular}

ns: nonsignificant $\quad *$ :significant $\quad * *$ : Very significant $\quad * * *$ : Highly significant

Table 2: The distribution of 11, 21, 12, 22 and 31 of teeth occurred the root fractures.

\begin{tabular}{|c|c|c|c|c|c|c|}
\hline Root fractures type & Tooth 11 & Tooth 21 & Tooth 12 & Tooth 22 & Tooth 31 & total \\
\hline Horizontal & 18 & 27 & 9 & 7 & 1 & 62 \\
\hline Oblique & 20 & 7 & 2 & 2 & 0 & 31 \\
\hline Horizontal- Oblique & 0 & 1 & 0 & 0 & 0 & 1 \\
\hline Fragmentary fracture & 2 & 0 & 0 & 0 & 0 & 2 \\
\hline Horizontal-vertical & 0 & 1 & 0 & 0 & 0 & 1 \\
\hline Total & 40 & 36 & 11 & 9 & 1 & 97 \\
\hline
\end{tabular}

horizontal and oblique root fracture, according to chisquaretest results, significant difference was found in the tooth no. 11 (Table $3,0.013^{*} P<0.05$ ).

When the existence of crown fracture along with root fracture was taken into consideration, spontaneous healing rate was found to be higher in the absence of crown fracture. Statistically significant difference was also detected (Table 4, $P<0.05$ ).

\section{Discussion}

Sudden and powerful impacts on teeth can cause root fractures, such as e.g. automobile accidents, sports injuries and fights. Dental injuries are most frequently observed in the maxillary anterior region (mainly central incisors) and reported to occur more frequently in maxi- llary teeth compared to mandibular teeth (9). Frequency of traumatic teeth injuries is mostly related to age and is reported to occur more frequently in the first 10 years of life. In the further years this frequency decreases and it is reported that dental injuries are less encountered at and above 30 years of age (17). Root fractures are most frequently observed in the 11-20 year age group male patients (18). In our study on 8-15 age intervals, it is determined that the highest rate of root fractures was in 11-13 age interval and in maxillary central incisors and male patients. Results of this study are consistent with the findings of other studies.

Root fractures are reported that occurrence mechanism of root fractures is usually in the form of a impingement from the frontal region and compression in labial and

Table 3: The distribution of fracture type and groups of age.

\begin{tabular}{|c|c|c|c|c|}
\hline \multirow{2}{*}{ Root fractures type } & \multicolumn{3}{|c|}{ Groups of Age } & \multirow{2}{*}{ Number of teeth } \\
\cline { 2 - 4 } & $\mathbf{8 - 1 0}$ & $\mathbf{1 1 - 1 3}$ & $\mathbf{1 4 - 1 5}$ & \\
\hline Horizontal & 14 & 38 & 10 & 62 \\
\hline Oblique & 6 & 21 & 4 & 31 \\
\hline Horizontal- Oblique & 0 & 0 & 1 & 1 \\
\hline Fragmentary fracture & 0 & 0 & 2 & 2 \\
\hline Horizontal-vertical & 0 & 1 & 0 & 1 \\
\hline Total & 20 & 60 & 17 & 97 \\
\hline
\end{tabular}


Table 4: The distribution of pulp necrosis and spontaneous healing according to whether coronal fracture along with the root fracture.

\begin{tabular}{|c|c|c|c|c|c|}
\hline \multirow{2}{*}{$\begin{array}{l}\text { Prognoses of pulp } \\
\text { after root fracture }\end{array}$} & & \multicolumn{2}{|c|}{ Coronal fracture } & \multirow[t]{2}{*}{ Total } & \multirow[t]{2}{*}{$P$} \\
\hline & & Available & Nonavailable & & \\
\hline $\begin{array}{l}\text { Spontaneous } \\
\text { healing }\end{array}$ & $\begin{array}{l}\text { Number of } \\
\text { root fractures }\end{array}$ & 28 & 38 & 66 & \\
\hline & $\%$ rates & $52,8 \%$ & $86,4 \%$ & $68,0 \%$ &, $001^{* * *}$ \\
\hline Pulp necrosis & $\begin{array}{c}\text { Number of } \\
\text { root fractures }\end{array}$ & 25 & 6 & 31 & \\
\hline & $\%$ rates & $47,2 \%$ & $13,6 \%$ & $32,0 \%$ & \\
\hline Total & $\begin{array}{c}\text { Number of } \\
\text { root fractures }\end{array}$ & 53 & 44 & 97 & \\
\hline
\end{tabular}

lingual or palatal direction (19). The injury in root fractures involves damage to pulp, dentin, cementum and periodontal ligament. Root fracture healing is effect of pulpal and periodontal healing processes and bacteria entering the coronal part of the pulp. Pulp necrosis was increased in enamel-dentin crown fracture teeth with extensive dentin exposure. Root fracture healing was significantly affected by pulp necrosis, dislocation fragments and luxation of the coronal fragment $(4,19)$. In this study, the occurrence crown fracture along with root fracture had increased in incidence of pulp necrosis. In additionally, rate of spontaneous healing was increased in root fractures with the absence of crown fracture. It was significant difference found as per chi-square tests in the vital spontaneous healing and pulp necrosis ratios $(P<0,05)$.

The some factors which had the important influence upon root fracture healing were: age, stage of root development, mobility and dislocation of the coronal fragment and distance of between the fracture fragments. The splinting procedures were usually absolute immobility in teeth with root fracture. Previous study reported that types of splinting were describes such as orthodontic band-arch wire splint, cap splint, composite splint, bonded metal wire splint and splinting with fiberglass. Rigid splinting could have a detrimental effect on root fracture healing (4). In this study, rigid splinting with composite was carried out only one patient, and it was developed pulp necrosis. For other patients, $0.5 \mathrm{~mm}$ fully circle orthodontic wire-composite was used for the purpose of splinting procedure. Splint was not carried out 49 teeth with root fractures which did not have luxation, had normal occlusion and mostly localised in apical 1/3. Spontaneous healing was observed on these teeth. These results are compatible with the results of a research conducted by Andreasen et al. (4).

Andreasen et al. reported that cervical fractures had observed pulp necrosis than fractures located at the middle or apical one-third of the root. In additionally, they said that optimal repositioning of root fractures with dislocation of the coronal fragment of up to $1 \mathrm{~mm}$ favors both healing with hard tissue and at the same time reduces the risk of pulp necrosis (24). In this study, apical $1 / 3$ root fractures were observed spontaneous healing than fractures located at the middle and cervical. Furthermore, in one case, with more than $3 \mathrm{~mm}$ dislocation of coronal fragment, was observed spontaneous healing after coronal fragment was repositioned and splinting procedure. Horizontal root fractures occur the majority frequently in the middle of the root and infrequently in the apical $1 / 3$ (18). In other study, apical and cervical $1 / 3$ root fractures had equal frequency whereas middle of root fractures are more frequent $(20,21)$. In our study, it was observed that root fractures were in apical $1 / 3$ area in 68 teeth, middle of root in 23 teeth, in cervical $1 / 3$ in 1 tooth and in more than one location in 5 teeth.

After fracture fragments are repositioned, splinting procedure is applied for a period of 4 weeks in middle of root fractures and 4 months in cervical $1 / 3$ root fractures $(18,20,21)$. The splinting period in our study was also applied in the same period.

Some researchers reported that apical $1 / 3$ fractures cannot be detected in Clinique and periapical x-ray graphic, but cervical root fractures could be traced clearly $(9,20)$. In our study, 3-D imaging was performed with the help of CBCT, thus, no problems were encountered in the identification of root fractures.

According to the epidemiological study performed by Çalışan et al., maxillary central incisor teeth were the most frequently affected $95 \%$ of root fractures and most common location of root fracture was in middle $1 / 3$ of the root $(21,22)$. In our study, root fractures in maxillary central incisor, maxillary lateral and mandibular central teeth were found as $78.35 \%, 20.61 \%$ and $1.03 \%$, respectively. These data obtained by us are compatible with the literature.

In radiographic evaluation of root fractures, it is recommended that periapical X-ray graph is taken with 45,90 and 110 degrees angles (20). In another study it is recommended that occlusal graphs should also be taken along with x-ray graph (21). Another study stated that for identification of root fractures, the fracture line could 
be angled for which reason 2 or $3 \mathrm{x}$-ray graphs should be taken from different angles. It is also reported that identification of root fracture before a complication occurs which causes the loss of tooth such as post-traumatic root resorption, which could be best diagnosed by CBCT (23). In our research no problems were encountered in diagnosing root fractures as 3-dimensional imaging technique was being used.

The studies was reported that CBCT device was of great significance in diagnosis of dental root fractures and periapical lesions and, in addition to endodontic surgery, implant planning $(11,14)$. It was also reported that mineralisation density which occurred with the healing in demineralised periapical lesion zones could be measured with HU ((Hounsfield units) scale (24). When all these researches are taken into consideration, it was believed that assessing root fractures with CBCT would be a good option and this study was conducted.

In conventional and digital oral radiographic three-dimensional anatomic dental structures can be viewed in 2-dimensional manner. On the other hand, CBCT devices can allow the clinician to identify in a shorter period of time root fractures which were diagnosed wrongly or not diagnosed at all with routine applications (9). In a study conducted on extracted molar teeth with CBCT and PR (periapical radiography), Bassam Hassan et al. found out that CBCT was superior in identifying vertical root fracture. They reported that in cases where x-rays did not pass from fracture lines, it would be difficult to identify root fractures with $\mathrm{x}$-ray graph and examination of 3-dimensional dental structures would not be adequate. In the light of these informations, they stated that CBCT yielded clearer information than $\mathrm{X}$-raygraph in identification of root fractures (6). Bernardes et al. compared conventional radiography and $\mathrm{CBCT}$ on 20 patients who received endodontic treatment with the suspect of root fracture and reported that CBCT was statistically superior to conventional radiography in identification of root fractures (7). Avsever et al. reported that in 2-dimensional radiographic images root fractures cannot be diagnosed accurately or cannot be diagnosed at all due to superposition of dental structures and anatomic formations (25). Micheal et al. compared CBCT and conventional radiography for assessing root fractures, as a result of which they reported that CBCT images were more superior to conventional radiography (26). In this study, teeth with real or suspected root fracture were examined in three-dimensional manner in three different planes and different cross-sections with CBCT. Detailed information has been obtained on location and type of fracture. Cases were examined from different cross-sections in axial, sagittal and coronal directions. In cross-sections from teeth of which image was taken, with images from different angles, more images and information was obtained compared to conventional x-ray graph. In cases which needed more information for treatment planning, CBCT has proved a very good guide and examination inspection tool. Particularly the cross-section images proved extremely beneficial in the identification of root fractures.

CBCT device can show differences in the amount of radiation that the patient is exposed to depending on the differences in scanning times, model of device and the length of irradiation used (25). At the same time, the amount of radiation is related to the thickness of voxel size. For this reason, it is recommended that as few cross-sections are taken as possible for diagnosis (26). In a study, it was reported that 0,3 voxel size was sufficient in dentistry practice and root fractures (27). In this study, CBCT was used to 0,3 voxel size and 8.9 seconds scanning time

Tomography allows for easier and more definite diagnosis in dental applications as it provides images at 3 planes and in 3 dimensions. In addition to the quality of obtained images and technical advantages of the device, another reason for preferring CBCT device over Multislice Computed Tomography-MSCT is that the patient is exposed to much lower radiation $(26,28)$. Some researchers reported that the received radiation is 13 times lower $(11,29,30)$. In addition, isotropic structure of the voxel ensures that the reshaped images are high quality and real-size, and it is reported that scanning was performed within 9 to 70 seconds $(11,26)$. For these reasons, CBCT device is preferred for its lower radiation for patients compared to medical computed tomography.

Ludlow et al. stated in a study that CBCT scanning caused the release of 4 to 42 times more doses compared to panoramic examinations, but the dose given to the patient decreased as the size of the image area narrowed (31).

Current results show that CBCT device is a perfect option for identifying root fractures; however, there are some cases where usage of conic ray technology is limited. Today, CBCT device cannot be found in every dental clinique due to its high cost (32). Scanning performed with CBCT device decrease the artifacts in images compared to conventional computed topographies, but as for patients with radiopaque materials such as sealer, gutta-percha and metals which are light-proof, artifact formation can still be observed and the quality of scanning can be reduced, which is a remarkable point for the importance and necessity of taking symptoms in consideration in verification of diagnosis $(33,34)$.

The effective dose from panoramic radiography is range from 5.5 to $22.0 \mu \mathrm{Sv}$, cephalometric radiography 2.2-3.4 $\mathrm{mSv}$, periapical radiography $1-8 \mathrm{mSv}$ and occlusal radiography $8 \mathrm{mSv}$, and $11-77 \mu \mathrm{Sv}$ in the area examined with CBCT device depending on the size, period and density of the area (35).

Although conic ray is an innovative and promising technology, effective radiation dose is higher compared to 
conventional oral and panoramic graphics. For this reason, it is considered that it is early to state that CBCT is a technique which should be used in all dental trauma cases. Today, CBCT must be considered as an alternative in cases when conventional radiography is insufficient in diagnosing root fractures.

\section{Conclusions}

This study results showed that:

Root fractures occurred more often in male and maxillary central incisor teeth.

The rate of pulp necrosis was increased in teeth which occurred crown fracture along with root fracture.

As a result of obtained image with $\mathrm{CBCT}$, according to location of root fractures, horizontal root fractures occurred more often than vertical and oblique root fractures. Cross-sectional images gain advantage from diagnose and classification of root fractures.

Root fracture line could be in different shape when root fractures evaluated with CBCT.

In literature review, $\mathrm{CBCT}$ images were more superior to conventional radiography for diagnose of root fractures.

\section{References}

1. Caldas AF, Burgos MEA. A retrospective study of traumatic dental injuries in a Brazilian dental trauma clinic. Dent Traumatol. 2001; 17:250-253.

2. Lauridsen E, Hermann NV, Gerds TA, Kreiborg S, Andreasen JO. Pattern of traumatic dental injuries in the permanent dentition among children, adolescents, and adults. Dent Traumatol. 2012;28:358-363. 3. Malmgren B, Andreasen JO, Flores MT, et al. International Association of Dental Traumatology guidelines for the management of traumatic dental injuries: 3. Injuries in the primary dentition. Dent Traumatol. 2012;28:174-182.

4. Andreasen JO, Andreasen FM, Mejàre I, Cvek M. Healing of 400 intra-alveolar root fractures. 2. Effect of treatment factors such as treatment delay, repositioning, splinting type and period and antibiotics. Dent Traumatol. 2004;20:203-211.

5. Heithersay GS, Kahler B. Healing responses following transverse root fracture: a historical review and case reports showing healing with (a) calcified tissue and (b) dense fibrous connective tissue. Dent Traumatol. 2013;29:253- 265.

6. Hassan B, Metska ME, Ozok AR, van der Stelt P, Wesselink PR. Detection of vertical root fractures in endodontically treated teeth by a cone beam computed tomography scan. J Endod. 2009;35:719- 22.

7. Bernardes RA, de Moraes IG, Húngaro Duarte MA, Azevedo BC, de Azevedo JR, Bramante CM. Use of cone-beam volumetric tomography in the diagnosis of root fractures. Oral Surg Oral Med Oral Pathol Oral Radiol Endod. 2009;108:270-277.

8. Kaya S, Yavuz I, Uysal I, Akkuş Z. Measuring Bone Density in Healing Periapical Lesions by Using Cone Beam Computed Tomography: A Clinical Investigation. JOE. 2012;38:28-31.

9. Kamburoğlu K, Cebeci ARİ, Gröndahl HG. Effectiveness of limited cone-beam computed tomography in the detection of horizontal root fracture. Dent Traumatol. 2009;25:256-261.

10. Doğan MS, Yavuz I, Tümen EC. Use Fields of Cone Beam Computed Tomography with Children. Turkiye Klinikleri J Pediatr DentSpecial Topics 2015;1:118-130.

11. Mora MA, Mol A, Tyndall DA, Rivera EM. In vitro assessment of local computed tomography for the detection of longitudinal tooth fractures. Oral Surg, Oral Med, Oral Pathol, Oral Radiol and Endod. 2007; 103:825-829.

12. Tamse A, Fuss Z, Lustig J, Kaplavi J. An evaluation of endodonti- cally treated vertikally fractured teeth. J Endod. 1999;25:506-8. 13. Kositbowornchai S, Sikram S, Nuansakul R, Thinkhamrop B. Root fracture detection on digital images: effect of the zoom function. Dent Traumatol.2003;19:154-159.

14. Youssefzadeh S, Gahleitner A, Dorffner R, Bernhart T, Kainberger FM. Dental vertikal root fractures: value of CT in detection. Radiology. 1999;210:545-549.

15. Clark SJ, Eleazer P. Management of a horizontal root fracture after previous root canal therapy. Oral Surg, Oral Med, Oral Pathol, Oral Radiol and Endod.2000;89:220-223.

16. Scarfe WC, Farman AG, Sukovic P. Clinical applications of conebeam computed tomography in dental practice. J Can Dent Assoc. 2006;72:75-80.

17. Eilert-Petersson E, Schelp L. An epidemiological study of bicycle-related injuries. Accid Anal Prev. 1997;29:363-72.

18. Erdemir A, Ungor M, Erdemir EO. Orthodontic movement of a horizontally fractured tooth: a case report. Dent Traumatol 2005;21:160-4.

19. Welbury RR, Kinirons MJ, Day P, Humphreys K, Gregg T A: Outcomes for root-fractured permanent incisors: a retrospective study. Pediatr Dent. 2002;24:98-102.

20. Shafie L, Farzaneh F, Hashemipour M. Repair of horizontal root fracture: A case report IEJ Iranian Endodontic Journal. 2011;6:176-8.

21. Neeraj M, Kundabala M, Shashi RA. A Review of Root Fractures: Diagnosis, Treatment and Prognosis. Dent Update. 2011;38:615616, 619-20.

22. Calişkan MK, Pehlivan Y. Prognosis of root-fractured permanent incisors. Endod Dent Traumatol. 1996;12:129-136.

23. Wölner-Hanssen AB, von Arx T. Permanent teeth with horizontal root fractures after dental trauma. Schweiz Monatsschr Zahnmed. 2010;120:200-12.

24. Kaan O, Umut A, Atakan K. Cone-Beam Computed Tomographic Evaluation of Spontaneously Healed Root Fracture. J Endod. 2010;36:1584-7.

25. Avsever H, Gunduz K, Orhan K, et al. Comparison of intraoral radiography and cone-beam computed tomography for the detection of horizontal root fractures: an in vitro study. Clin Oral Investig. 2014; 18:285-92 .

26. Michael B, Andrea BW, Pedram S, Thomas A. Comparison of intraoral radiography and limited cone beam computed tomography for the assessment of root-fractured permanent teeth. Dent Traumatol . 2009;25:571-7.

27. Ludlow JB, Davies-Ludlow LE, Brooks SL. Dosimetry of two extraoral direct digital imaging devices: NewTom cone beam CT and Orthophos Plus DS panoramic unit. Dentomaxillofac Radiol. 2003;32:4:229-34.

28. Scarfe WC, Farman AG, Sukovic P. Clinical Applications of Cone-Beam Computed Tomography in Dental Practice. J Can Dent Assoc. 2006;72:75-80.

29. Kamburoğlu K, Murat S, Yüksel SP, Cebeci AR, Horasan S. Detection of vertikal root fracture using cone-beam computerized tomography: an in vitro assessment. Oral Surg, Oral Med, Oral Pathol, Oral Radiol and Endod. 2010;109:74-81.

30. Holberg C, Steinhauser S, Geis P, Rudzki-Janson I. Cone-beam computed tomography in orthodontics: benefits and limitations. J OrofacOrthop. 2005;66:434-44.

31. Arai Y, Honda K, Iwai K, Shinoda K. Practical model "3DX" of limited cone-beam X-ray CT for dental use. International Congress Series. 2001;1230:713-8.

32. Mah JK, Danforth RA, Bumann A, Hatcher D. Radiation absorbed in maxillofacial imaging with a new dental computed tomography device. Oral Surg, Oral Med, Oral Pathol, Oral Radiol and Endod 2003; 96: 508 -513.

33. Ludlow JB. Comment on "effective dose range for dental cone beam computed tomography scanners".Eur J Radiol. 2012;81:421920.

34. Cotton TP, Geisler TM, Holden DT, Schwartz SA, Schindler WG. Endodontic applications of cone-beam volumetric tomography. J En- 
dod. 2007; 33:1121-32.

35. Scarfe WC, Levin MD, Gane D, Farman AG. Use of cone beam com-

puted tomography in endodontics. Int J Dent. 2009;2009:634567.

\section{Conflicts of Interest}

The authors declare that they have no conflict of interest. 